\title{
A new tool for in vivo manipulation of brain microRNA levels: the work of Smalheiser et al. (2014)
}

\author{
Don A. Baldwin* \\ Signal Biology, Inc., Philadelphia, PA, USA \\ *Correspondence: support@signalbiology.com \\ Edited by: \\ Robert W. Williams, University of Tennessee Health Science Center, USA \\ Reviewed by: \\ Julie A. Saugstad, Oregon Health \& Science University, USA
}

Keywords: enoxacin, cortex, miRNA, rat learned helplessness, depression

\section{A commentary on}

Enoxacin elevates microRNA levels in rat frontal cortex and prevents learned helplessness

by Smalheiser NR, Zhang $H$, Dwivedi Y. Front Psychiatry (2014) 5:6. doi: 10.3389/fpsyt.2014.00006

Complex molecular networks often pose significant challenges for separating causes from effects, especially when using in vivo models to conduct experiments. Tackling such a challenge requires at least three (and usually more) critical tools: a means to reliably manipulate individual molecular factors, a measurable reporter with valid connections to the cell/tissue/organism behavior of interest, and an experimental system that allows repeated measurements over time. Smalheiser, Zhang, and Dwivedi describe a rat model that may provide these tools for studying molecular mechanisms of major depressive disorder (MDD).

Major depressive disorder encompasses a wide range of neurological symptoms, perhaps reflecting the wide variety of cellular and molecular alterations which have been reported in multiple brain regions (1). Smalheiser et al. have observed reduced microRNA expression levels in the prefrontal cortex of depressed suicide subjects $(2,3)$, but learned helplessness induced in a rat model of MDD was accompanied by muted responses in specific microRNAs compared to significantly reduced expression in rats that did not develop learned helplessness (4). As potent down-regulators of messenger RNA abundance and translation, microRNAs target a majority of genes in the human genome and thus represent a global, and potentially druggable $(5,6)$, regulatory mechanism capable of affecting most molecular networks. But do alterations in microRNA expression precede and potentially cause depression severe enough to result in suicide, comprise part of the response to some other triggering pathology, or represent both cause and effect depending on which microRNA is involved (7)?

Two factors that most influence microRNA expression levels are transcription regulation and RNA processing. microRNAs are short portions of sequence cleaved from longer precursor transcripts. Stabilization of the Dicer complex, the enzyme responsible for transcript cleavage to produce mature microRNAs, will result in higher levels of microRNA as long as unprocessed precursor transcripts are available. This effect can be achieved by supplying enoxacin, a fluoroquinolone that binds to a member of the Dicer complex and increases overall microRNA levels in cultured cells (8). Fluoroquinolones are an interesting family of small molecules that exhibit a number of bioactive properties; enoxacin not only interacts with TAR RNA-binding protein 2 (TARBP2) to promote Dicer activity but also alters V-ATPase binding to actin (9), JNK signaling (10), and cytochrome P450 activities (11-13), as well as inhibiting prokaryotic DNA gyrases (14).

Smalheiser et al. hypothesized that boosting microRNA abundances, or at least preventing their reduction, may disrupt the onset of learned helplessness in the rat MDD model, but it was not previously known whether enoxacin would be available to or active in the brain. Their current work demonstrates that 1 week of enoxacin exposure indeed does raise the levels of four neuronal reporter microRNAs in rat frontal cortex compared to unexposed controls. In parallel experiments, inescapable shock induced learned helplessness in 6 of 10 untreated rats, but only of 5 of 34 rats pretreated with enoxacin developed learned helplessness. These findings establish an experimental system that can now be used for a variety of follow-up studies using the three key tools - enoxacin to manipulate brain microRNA, learned helplessness as the reporter measurement, and permutations of timing and dosage to investigate time courses of causes and effects. A potentially useful addition would be assays of blood microRNA as a surrogate for brain expression levels, allowing repeated testing of animals without sacrificing to collect brain tissue; circulating microRNAs are becoming a well-established class of biomarkers for several pathologies including traumatic brain injury (15). Important topics to be addressed include the efficacy of enoxacin treatment after the onset of learned helplessness, and brain RNA and protein profiling to catalog the affected microRNAs, genes, and anatomical regions. As with any model system several caveats must be considered, such as whether the antidepressive effect is due to enoxacin interaction with some other protein rather than stabilization of Dicer, and how well this rat model represents human MDD at brain biochemical up through behavioral levels.

As a bacterial DNA gyrase inhibitor, enoxacin has been successfully used worldwide as a second-generation quinolone 
antibiotic with low occurrence of adverse effects, although a perception of higher toxicity compared to related compounds has limited its use in the United States. Perhaps fortelling the cortical microRNA result, enoxacin has been associated with central nervous system effects including insomnia, photosensitivity, and convulsions (when combined with NSAIDs) (16, 17). Interest in enoxacin has been renewed by cancer microRNA profiling, which revealed wide-scale reductions in expression, including the loss of many tumorsuppressor microRNAs. Barring somatic mutation of TARBP2 that would prevent its binding, enoxacin can alleviate suppressed microRNA production and restore molecular controls that normally prevent tumorigenesis or send neoplastic cells into cell cycle arrest or apoptosis $(6,8,18,19)$. Reduced microRNA production is associated with amyotrophic lateral sclerosis and other neurodegeneration $(7,20-24)$, and enoxacin is therefore under consideration as a treatment for motor neuron diseases (25). Another potential therapeutic application (likely not involving microRNA) is inhibition of osteoclast development and activity, which could prevent damaging bone resorption in periodontal disease and around orthopedic implants that lose stability with wear $(9,10,26,27)$. Would MDD patients, who may need a much longer course of enoxacin exposure than is typical for antibiotic indications, experience relief of depression and protection against cancer at the expense of excessive bone deposition and an altered microbiome? At a minimum, enoxacin provides a well-tolerated tool for in vivo investigation of how microRNA processing affects brain phenotypes (28), and a starting point for identifying specific therapeutic targets that could be treated with synthetic microRNAs or their antisense inhibitors (29-31).

\section{REFERENCES}

1. Dwivedi Y. Emerging role of microRNAs in major depressive disorder: diagnosis and therapeutic implications. Dialogues Clin Neurosci (2014) 16:43-61.

2. Smalheiser NR, Lugli G, Rizavi HS, Torvik VI, Turecki G, Dwivedi Y. microRNA expression is down-regulated and reorganized in prefrontal cortex of depressed suicide subjects. PLoS One (2012) 7:e33201. doi:10.1371/journal.pone. 0033201
3. Smalheiser NR, Lugli G, Zhang H, Rizavi H, Cook EH, Dwivedi Y. Expression of microRNAs and other small RNAs in prefrontal cortex in schizophrenia, bipolar disorder and depressed subjects. PLoS One (2014) 9:e86469. doi:10.1371/journal. pone.0086469

4. Smalheiser NR, Lugli G, Rizavi HS, Zhang H, Torvik VI, Pandey GN, et al. microRNA expression in rat brain exposed to repeated inescapable shock: differential alterations in learned helplessness vs. non-learned helplessness. Int J Neuropsychopharmacol (2011) 14:1315-25. doi:10.1017/ S1461145710001628

5. Gidlof O, Erlinge D. microRNAs in the failing heart - novel therapeutic targets? Scand Cardiovasc J (2014) 48:328-34. doi:10.3109/14017431.2014. 983965

6. MacDonagh L, Gray SG, Finn SP, Cuffe S, O’Byrne KJ, Barr MP. The emerging role of microRNAs in resistance to lung cancer treatments. Cancer Treat Rev (2015) 41(2):160-9. doi:10.1016/j.ctrv.2014. 12.009

7. Gascon E, Gao FB. Cause or effect: misregulation of microRNA pathways in neurodegeneration. Front Neurosci (2012) 6:48. doi:10.3389/ fnins.2012.00048

8. Melo S, Villanueva A, Moutinho C, Davalos V, Spizzo R, Ivan C, et al. Small molecule enoxacin is a cancer-specific growth inhibitor that acts by enhancing TAR RNA-binding protein 2mediated microRNA processing. Proc Natl Acad Sci U S A (2011) 108:4394-9. doi:10.1073/pnas. 1014720108

9. Toro EJ, Ostrov DA, Wronski TJ, Holliday LS. Rational identification of enoxacin as a novel V-ATPase-directed osteoclast inhibitor. Curr Protein Pept Sci (2012) 13:180-91. doi:10.2174/ 138920312800493151

10. Liu X, Qu X, Wu C, Zhai Z, Tian B, Li H, et al. The effect of enoxacin on osteoclastogenesis and reduction of titanium particle-induced osteolysis via suppression of JNK signaling pathway. Biomaterials (2014) 35:5721-30. doi:10.1016/j.biomaterials. 2014.04.006

11. Fuhr U, Anders EM, Mahr G, Sorgel F, Staib AH. Inhibitory potency of quinolone antibacterial agents against cytochrome P450IA2 activity in vivo and in vitro. Antimicrob Agents Chemother (1992) 36:942-8. doi:10.1128/AAC.36. 5.942

12. Kinzig-Schippers M, Fuhr U, Zaigler M, Dammeyer J, Rusing G, Labedzki A, et al. Interaction of pefloxacin and enoxacin with the human cytochrome P450 enzyme CYP1A2. Clin Pharmacol Ther (1999) 65:262-74. doi:10.1016/S0009-9236(99)70105-0

13. Sanderink GJ, Bournique B, Stevens J, Petry M, Martinet M. Involvement of human CYP1A isoenzymes in the metabolism and drug interactions of riluzole in vitro. J Pharmacol Exp Ther (1997) 282:1465-72.

14. Yoshida H, Nakamura M, Bogaki M, Ito H, Kojima $\mathrm{T}$, Hattori $\mathrm{H}$, et al. Mechanism of action of quinolones against Escherichia coli DNA gyrase. Antimicrob Agents Chemother (1993) 37:839-45. doi:10.1128/AAC.37.4.839

15. Redell JB, Moore AN, Ward NH III, Hergenroeder GW, Dash PK. Human traumatic brain injury alters plasma microRNA levels. J Neurotrauma (2010) 27:2147-56. doi:10.1089/neu.2010.1481

16. Ball P, Tillotson G. Tolerability of fluoroquinolone antibiotics. Past, present and future. Drug Saf (1995) 13:343-58. doi:10.2165/00002018199513060-00004

17. Rafalsky V, Andreeva I, Rjabkova E. Quinolones for uncomplicated acute cystitis in women. Cochrane Database Syst Rev (2006) (3):CD003597. doi:10. 1002/14651858.CD003597.pub2

18. Cornaz-Buros S, Riggi N, DeVito C, Sarre A, Letovanec I, Provero P, et al. Targeting cancer stem-like cells as an approach to defeating cellular heterogeneity in Ewing sarcoma. Cancer Res (2014) 74:6610-22. doi:10.1158/0008-5472.CAN14- 1106

19. Sousa E, Graca I, Baptista T, Vieira FQ, Palmeira C, Henrique R, et al. Enoxacin inhibits growth of prostate cancer cells and effectively restores microRNA processing. Epigenetics (2013) 8:548-58. doi:10.4161/epi.24519

20. Haramati S, Chapnik E, Sztainberg Y, Eilam R, Zwang R, Gershoni N, et al. miRNA malfunction causes spinal motor neuron disease. Proc Natl Acad Sci U S A (2010) 107:13111-6. doi:10.1073/pnas. 1006151107

21. Kabashi E, Valdmanis PN, Dion P, Spiegelman D, McConkey BJ, Vande Velde C, et al. TARDBP mutations in individuals with sporadic and familial amyotrophic lateral sclerosis. Nat Genet (2008) 40:572-4. doi:10.1038/ng.132

22. Lagier-Tourenne C, Polymenidou M, Cleveland DW. TDP-43 and FUS/TLS: emerging roles in RNA processing and neurodegeneration. Hum Mol Genet (2010) 19:R46-64. doi:10.1093/hmg/ ddq137

23. Rademakers R, Eriksen JL, Baker M, Robinson T, Ahmed Z, Lincoln SJ, et al. Common variation in the miR-659 binding-site of GRN is a major risk factor for TDP43-positive frontotemporal dementia. Hum Mol Genet (2008) 17:3631-42. doi:10.1093/hmg/ddn257

24. Kawahara Y, Mieda-Sato A. TDP-43 promotes microRNA biogenesis as a component of the Drosha and Dicer complexes. Proc Natl Acad Sci U S A (2012) 109:3347-52. doi:10.1073/pnas. 1112427109

25. Hornstein E, Emde A.M. Methods of Diagnosing and Treating Motor Neuron Diseases. World Intellectual Property Organization. Patent Application WO 2014/020608 A1 (2014).

26. Oktay S, Chukkapalli SS, Rivera-Kweh MF, Velsko IM, Holliday LS, Kesavalu L. Periodontitis in rats induces systemic oxidative stress that is controlled by bone-targeted antiresorptives. J Periodontol (2015) 86:137-45. doi:10.1902/jop.2014. 140302

27. Rivera MF, Chukkapalli SS, Velsko IM, Lee JY, Bhattacharyya I, Dolce C, et al. Bis-enoxacin blocks rat alveolar bone resorption from experimental periodontitis. PLoS One (2014) 9:e92119. doi:10.1371/ journal.pone.0092119

28. Most D, Workman E, Harris RA. Synaptic adaptations by alcohol and drugs of abuse: changes in microRNA expression and mRNA regulation. Front Mol Neurosci (2014) 7:85. doi:10.3389/ fnmol.2014.00085 
29. Cheng CJ, Bahal R, Babar IA, Pincus Z, Barrera F, Liu C, et al. MicroRNA silencing for cancer therapy targeted to the tumour microenvironment. Nature (2015) 518(7537):107-10. doi:10. 1038/nature13905

30. Scott KA, Hoban AE, Clarke G, Moloney GM, Dinan TG, Cryan JF. Thinking small: towards microRNA-based therapeutics for anxiety disorders. Expert Opin Investig Drugs (2015) 24(4):529-42. doi:10.1517/ 13543784.2014 .997873

31. Wang H, Jiang Y, Peng H, Chen Y, Zhu P, Huang Y. Recent progress in microRNA delivery for cancer therapy by non-viral synthetic vectors. Adv Drug Deliv Rev (2015) 81C:142-60. doi:10.1016/j.addr. 2014.10.031

Conflict of Interest Statement: The author declares that the research was conducted in the absence of any commercial or financial relationships that could be construed as a potential conflict of interest.

Received: 30 January 2015; accepted: 13 March 2015; published online: 20 April 2015.

Citation: Baldwin DA (2015) A new tool for in vivo manipulation of brain microRNA levels: the work of
Smalheiser et al. (2014). Front. Psychiatry 6:44. doi: 10.3389/fpsyt.2015.00044

This article was submitted to the journal Frontiers in Psychiatry.

Copyright (c) 2015 Baldwin. This is an open-access article distributed under the terms of the Creative Commons Attribution License (CC BY). The use, distribution or reproduction in other forums is permitted, provided the original author(s) or licensor are credited and that the original publication in this journal is cited, in accordance with accepted academic practice. No use, distribution or reproduction is permitted which does not comply with these terms. 